\title{
Research on Integrated Teaching Strategy to Improve the Effect of Badminton Teaching in Colleges and Universities
}

\author{
Xiunian Huang \\ College of P.E. Science, Lingnan Normal University, Zhanjiang 524048, Guangdong, China
}

\begin{abstract}
While badminton is widely sought after by college students, the teaching effect of badminton course in many colleges and universities is poor. Starting from the existing problems, combined with teaching experience and literature analysis, this paper puts forward an integrated strategy to improve college badminton teaching, such as updating teaching ideas, optimizing teaching contents, innovating teaching process and improving teaching evaluation, in order to provide reference for college physical education reform.
\end{abstract}

Keywords: Badminton teaching, Integrated strategy, Teaching effect, Colleges and universities.

\section{Introduction}

In 2018, general secretary Xi Jinping pointed out at the National Education Conference: "we must establish a healthy first education concept, help students enjoy the fun, enhance physical fitness, perfect personality and temper their will" in the four goals of physical exercise[1]. On October 15, 2020, the general office of the CPC Central Committee and the general office of the State Council issued the opinions on Comprehensively Strengthening and improving school physical education in the new era, which put forward a new physical education curriculum model of "church, diligent practice and regular competition", which immediately became the focus of attention and the focus of research and practice of experts, scholars and front-line teachers. These two points point out the direction for the reform of physical education in the new era, and also provide a strong guarantee for the formation of lifelong physical education. With the gradual deepening of China's educational reform, how to improve the teaching effect of college physical education classroom is the focus of college physical education teaching. Badminton is sought after by college students because of its simplicity, easy to learn, skill, interest and competitiveness, and high exercise value. However, through the investigation, it is found that the teaching effect of badminton courses in many colleges and universities is not high. The reasons are mainly reflected in the low quality of teachers, backward teaching ideas, single methods, too many teaching contents, unreasonable evaluation mechanism, poor foundation of students, large individual differences, inadequate integrated teaching organization inside and outside class, etc. This is inconsistent with the educational goal of "four in one" of physical education in the new era, the guiding ideology of "health first" and the requirements of developing students' quality in an all-round way.

Due to the long-term existence of backward educational concepts, complex, shallow, partial and broken teaching contents in the previous physical education curriculum teaching in primary and secondary schools in China, as well as the limitations of teaching conditions, it has caused the embarrassing situation that Chinese primary and secondary school students failed to master a sports skill after 12 years of physical education learning. Therefore, college teachers often start from "zero" when teaching sports skills. In recent years, badminton courses are gradually popularized in Colleges and universities. Badminton is favored by college students because of its unique fitness and entertainment. However, according to the author's teaching situation in the past ten years, the teaching of badminton course from "zero" has not been significantly improved.

Physical education as an important part of school education, the effectiveness of its teaching reform also directly affects the effectiveness of the whole school education and teaching reform. Badminton teaching is an important part of physical education in Colleges and universities, and the university stage is the last stop of students' physical education. Whether students can master one or two physical skills during the university is the key to whether they can form lifelong physical exercise ability and habits and develop healthy behavior. Therefore, improving the effect of badminton teaching in Colleges and universities is particularly important to cultivate college students' core quality of physical education and develop the sports ability of lifelong physical education. Based on the in-depth analysis of the current situation and existing problems of badminton teaching in Colleges and universities, this paper focuses on the core of physical education reform and integrates the strategies to improve the effect of badminton teaching in Colleges and universities, in order to provide reference for the reform of physical education in Colleges and universities.

\section{Important Factors Affecting the Effect of Physical Education Teaching}

Dr. Yu Sumei, deputy director of the Institute of sports, health and art of the Chinese Academy of Educational Sciences, believes that among the factors affecting the quality of physical education teaching, there are both human and material factors and other factors. People, things and things all affect or determine the teaching quality to varying degrees[2]. First of all, the human factor can not be ignored. People not only dominate the classroom and dominate the curriculum, but also grasp the results of the classroom according to people's different abilities and characteristics. The human factor in physical education teaching is mainly composed of teachers and students. Teachers' teaching and students' 
learning together constitute the whole teaching process. In the teaching process, only when teachers' leading role and students' main role are brought into full play and coordinated, can the teaching effect of physical education be better reflected. Secondly, the physical factors involved in physical education teaching not only include whether the field equipment can meet the needs of the classroom and whether the use is reasonable and safe; We should also consider the rationality of the selection of teaching content and the impact of weather and environmental factors on class. Finally, it is the factors in physical education teaching, including lesson preparation, the design of teaching objectives, the selection and application of teaching methods, the operation process and methods of teaching evaluation, the inspection and prevention of potential safety hazards in the teaching process, and so on. In the process of teaching, if you don't grasp the factors of things, the teaching effect will be greatly reduced.

\section{Integrated Strategies to Improve the Effect of Badminton Teaching in Colleges and Universities}

\subsection{Update Teaching Concepts and Improve Teachers' Professional Quality}

The traditional physical education teaching concept pays attention to the teaching of single knowledge and technology, and the teaching methods are single, which is mainly manifested in the "indoctrination" teaching in which teachers teach and students learn collectively. Ignoring the structural characteristics of knowledge and skills, students' individual differences and interest needs, the result is that the teaching atmosphere of the whole class is relatively dull, students' learning enthusiasm is not high and the effect is low. In addition, due to the focus on the teaching of single technology, the traditional physical education has the "three noes" characteristics of no exercise, no tactics and no competition[3]. Therefore, physical education in the new era requires that the teaching concept should be changed from "teaching determines learning" to "learning determines teaching". The so-called "teaching by learning" is to change the single way of teaching and learning, take students as the center, and determine what to teach and how to teach according to the learning situation. Specific to the classroom, we can adjust and improve teaching methods and organize teaching activities more effectively according to the students' learning situation in the classroom. We should implement the teaching concept of "teaching by learning" in the process of class. Teachers need to grasp the following key points. First, we should always adhere to the guidance of "comprehensive education", and firmly grasp students' cognitive laws, interests and sports needs. Second, fully consider the learning situation from the beginning of lesson preparation. Pay attention to the learning situation and differences in class, so as to teach students according to their aptitude, so that every student can develop. The third is to timely adjust the learning methods, optimize the teaching methods and improve the effectiveness of teaching in combination with the process and effect of students' learning. Fourth, reasonably organize "learning, practice and competition" activities to help students achieve the goal of "enjoying fun, enhancing physique, improving personality and tempering will". "Teaching by learning" not only requires teachers to change their teaching ideas and improve their level, but also correctly guide students to actively participate, seriously learn and practice, master learning methods and interact. In the teaching process, only by reasonably grasping the leading role of teachers and the effective play of students' main role can we achieve the ideal teaching effect.

"If a worker wants to do well, he must sharpen his tools first." Teachers are the promoters and main forces of teaching reform and the necessary conditions for effective teaching. The teaching concept, professional quality and teaching ability of physical education teachers directly determine the quality of teaching. However, at present, badminton teachers in Colleges and universities in China generally have low professional quality. Most badminton teachers have served as badminton teaching through self-study or short-term training. This is particularly prominent in the teaching of general badminton courses in Colleges and universities. Due to the lack of professional theory and practical experience, these teachers are not reasonable in teaching methods and organization, and the explanation and demonstration are not accurate enough. They can not let students establish correct concepts and action images, stimulate students' interest, and the teaching effect is relatively poor. Therefore, in order to improve the teaching quality, we must strengthen the improvement of teachers' professional quality, systematically plan the targeted training for physical education teachers, and take "going out and inviting in". First, hire qualified retired athletes as coaches. At the same time, encourage and strongly support teachers to often participate in theoretical and skill training on educational reform ideas and badminton teaching and training, accurately grasp the direction of physical education reform through training, and constantly improve teachers' teaching ideas, professional level and educational and teaching ability, Deeply understand the connotation and specific requirements of the implementation of "church, diligent practice and regular competition", more effectively organize classroom teaching, and then improve the teaching effect.

\subsection{Optimize the Teaching Content and Set up Flexible and Diverse Competition Scenes}

Badminton techniques and tactics are rich and diverse, and the technical requirements are relatively high. Therefore, if you want to master the skills and tactics of badminton and reach a certain level of skills and tactics, you need long-term, systematic and scientific training. However, most of the elective badminton courses in Colleges and universities in China only have one semester. It is possible to learn all the techniques and tactics in one semester. Therefore, in the selection of teaching content, we must make a reasonable choice and grasp the most basic and main techniques and tactics for teaching. For example: technology to serve and receive, backcourt high-range ball, kill ball; The techniques of net shot, lift in the front field, picking the ball, catching and blocking the net in the middle field and the corresponding footwork movement are mainly used. The skills of drop shot, net shot, net kill, corner kick, drive and backhand high clear ball with high technical difficulty are only required to be mastered by individual students with good foundation. 
After students master certain basic skills and footwork, they should create flexible and diverse "competitions" in time. The form can be a single skill training competition or a comprehensive teaching competition. Through the competition, the timely application of the learned technology to the competition can better stimulate students' learning enthusiasm and promote the internalization and absorption of technology. At the same time, during the competition, check the proficiency of technical mastery, and find out the deficiencies, and then improve them. In addition, through the competition, students can not only really understand the movement law of badminton, experience the happiness brought by badminton and form lifelong sports; We can also learn to abide by the rules, fair competition and tenacious physical education, improve our personality and realize the purpose of comprehensive education of physical education.

\subsection{Innovative Teaching Process}

The innovation of teaching process is mainly reflected in the transformation of teaching ideas, the determination of teaching objectives, and the innovation of teaching methods and organizations. In order to realize the teaching goal of "four in one" in Physical Education in the new era, we should deeply understand and grasp the teaching idea of "church, diligent practice and regular competition" and earnestly implement it.

\subsubsection{Concept and Meaning of Teaching}

"Teaching" means that physical education teachers should help students master sports and health knowledge, basic sports skills and special sports skills to meet the needs of lifelong physical exercise and individual development. It is the basis of diligent practice and regular competition. "Teaching" contains three meanings, that is, students should be able to "speak, do and use", which is the three progressive processes of the church. "Can speak" not only understands, but also can clearly express the feelings of learned knowledge and skills in language; "Being able to do" is to master the concept, remember the concept and master the skills; "Being able to use" is not only the embodiment of ability, but also the ability to skillfully apply the learned skills to the competition. The realization of the church involves many factors, but from the perspective of classroom teaching, the key to "church" lies in "teaching" and "good teaching", that is, in following the laws of education and teaching, grasping the laws of movement formation and students' cognitive laws, finding reasonable teaching methods and teaching scientifically[4].

3.3.1.1 Improve the teaching effect with the help of multimedia information technology

Nowadays, network multimedia has promoted the rapid development of all walks of life with its characteristics of fast, convenient, extensive resources and not limited by time and space. In the field of education, multimedia information technology and education and teaching are also rapidly and deeply integrated, which has changed the whole teaching environment, teachers' teaching view and students' learning view. Many convenient and efficient teaching modes and methods such as "flipped classroom", "SPOC", "Mu class", "micro class" have also emerged. Therefore, as a physical education teacher, we should also be able to keep pace with the times, understand and master the application of information technology in physical education teaching, and improve the teaching quality of physical education classroom. In the teaching process, through the flexible use of mixed teaching methods, such as the "flipped classroom" teaching method, teachers make the teaching contents, key points and requirements into text, pictures or videos before class, and send them to students through Wechat, QQ and other media, so that students can preview in advance. The teaching method of explanation and demonstration in Teachers' traditional teaching is changed to arranging homework after class before class, and individual guidance and problem discussion are adopted in teaching. This teaching method not only emphasizes the main role of students, cultivates students' enthusiasm for active learning, strengthens the cultivation of application ability, but also reflects the leading role of teachers[5]. In case of wrong actions during students' practice, teachers can record the wrong actions with mobile phones, so that students can more intuitively understand their problems, and better results will be achieved through teachers' targeted guidance.

3.3.1.2 Pay attention to students' differences, treat them differently and teach students according to their aptitude

In the teaching process, teachers should strive to treat students differently according to their different differences in cognition, physical quality and sports foundation, teach students according to their aptitude and teach in groups reasonably, so that each student can grow and progress. Put forward higher requirements for students with good sports foundation, promote their better development and form sports expertise; For students with poor sports foundation, we should step by step and give patient guidance and help to improve their sports and stimulate their interest and confidence in learning; We should pay more attention to and care for students with sports disabilities, give them targeted sports and health guidance, and make them feel the joy and gain of sports. According to different teaching contents, create a positive, cooperative and challenging teaching situation, so that every student can make progress through their own efforts, experience the happiness and sense of achievement of learning, and improve the internal motivation of learning[6].

\subsubsection{Grasp the three key points of badminton teaching}

In the process of teaching, we should always grasp the three key points of badminton teaching - hitting point, force and racket surface control[7]. First of all, any technology of badminton has its best hitting point. When hitting the ball, only on the basis of accurate judgment of the incoming ball and finding the best hitting point can we ensure the smooth and control of force, and then ensure the initiative of hitting the ball. Otherwise, the best radian and landing point cannot be played, resulting in passive return; Secondly, badminton requires small hitting action, concentrated force and highlighting the characteristics of instantaneous explosive force. Therefore, when explaining the action essentials, it must be emphasized that the force during hitting is instantaneous force based on the relaxation of relevant muscle groups, so as to ensure the force effect during hitting; In addition, when hitting the ball, the control of the racket 
surface and the hitting position are the key to ensure the hitting arc, landing point and force effect. For example, when the front racket hits the ball, the power of hitting the ball can be fully applied to the ball, while cutting the racket will lose part of the power of hitting the ball. Different hitting positions determine the change of landing point. To sum up, in the teaching process, teachers and students can ensure good teaching effect only by grasping these three keys for teaching and learning.

3.3.1.4 Pay attention to the consistency of similar technologies and the "pithy formula" teaching of action essentials

In badminton, the technical basis of similar technologies has great similarity, which is a significant feature of badminton technology. Such as "high clear, drop shot and smash" in the backcourt, "net shot, net lift and hooking" in the forecourt, and "hooking, blocking" and "pumping and picking" in the midfield. These similar technologies have great similarities in the early action of hitting the ball except that they are slightly different at the moment of hitting the ball. Badminton is a competitive sport with strong skills and antagonism. In the competition, whoever can get the advantage of speed in the process of fighting each other can get the initiative of the competition and finally win the competition. In the game, the consistency of similar technical actions is directly related to whether it can delay and destroy the opponent's judgment and response to your shot, and whether it can destroy the opponent's game rhythm. Therefore, we must pay attention to the consistency of similar technologies in the teaching process. In addition, when teaching technical movements, we should also pay attention to the "pithy formula" teaching of movement essentials, such as "grabbing the front, grabbing the high and pressing down quickly" of kill techniques; drop shot technology "grab the front, grab the high, cut the bag and press down"; The "three movements" of serve high and long ball technology, moving the center of gravity, rotating the body and flashing the force; When teaching defensive skills, we emphasize the three elements of "reasonable position, instant cushion step and forward stroke". It not only grasps the core of technical action, but also makes it concise and easy to understand, which improves the effect of learning.

\subsubsection{Diligent training}

"Diligent practice" is a process in which students can master and use flexibly through targeted and repeated practice on the basis of learning sports health knowledge and sports skills. From the law of the formation of sports skills, "diligent practice" is the only way to further stimulate students' interest in learning and finally form sports ability. Because, only with the guarantee of diligent practice, can we master the learned technology skillfully, and can we use it in the competition. With the experience of successful application, students can enjoy happiness in the competition, develop the habit of participating in exercise, and finally develop the behavior of physical education. However, "diligent practice" should also grasp the two key points of quality and quantity. Degree is to practice enough times, quantity is to practice correctly, and the method should be reasonable, otherwise it can only backfire.
3.3.3.1 Establish an integrated teaching mode inside and outside the class and make great efforts in the implementation

Both the formation of sports skills and the enhancement of physical quality can only be obtained through long-term, repeated and targeted training. It is far from enough to rely on classes twice a week. Therefore, in addition to arranging sufficient time for practice and competition in classroom teaching, teachers should also attach great importance to the organic combination of in class teaching and extracurricular sports activities. Actively organize, guide and guide students to participate in extracurricular sports activities and expand the time and space of practice, so as to promote students to apply the special sports knowledge and skills learned in class to extracurricular physical exercise, sports community activities and sports competitions. Cultivate students to adhere to the habit of physical exercise, promote students to better form the core quality of the discipline, and lay a solid foundation for the formation of lifelong sports.

\subsubsection{Make up the shortcomings and comprehensively improve the school running conditions}

The effective implementation of "diligent training" cannot be guaranteed without sufficient venues and equipment. However, the survey found that many colleges and universities have some problems in physical education teaching, such as few types of sports equipment, insufficient area of sports venues, lack of excellent teachers and so on. In the opinions on Comprehensively Strengthening and improving school physical education in the new era issued by the office of the State Council in mid October 2020, it is emphasized that "make up for the shortcomings of teachers, venues and equipment, promote the balanced development of school physical education, and build venues, facilities and special classrooms to meet the needs of curriculum teaching and practical activities". Raise awareness, build or transform sites through multiple channels and ways, and fundamentally solve the dilemma of more people and less sites.

\subsubsection{Regular matches}

"Regular competition" is to often organize all kinds of sports competitions at all levels to promote students to use skills, enhance physique, improve personality and develop in an all-round way. The focus of regular competition is full participation, which means that all students have the opportunity to participate in sports competitions, not a few students. The form of competition can be varied. In the classroom, the teaching competition can be reasonably organized according to the teaching content. After class, ordinary colleges and universities establish sports teams, secondary college teams, clubs and badminton associations, build a normal campus sports competition mechanism, actively carry out after-school sports training, and widely carry out class and grade sports competitions. The school holds a comprehensive sports meeting or sports festival at least once a year through rich and colorful campus sports competitions, Attract the majority of students to actively participate in physical exercise. Often holding various forms of competitions to provide students with a stage to show their skills is an effective way to stimulate students' interest in learning and enhance their learning motivation. 


\subsection{Accurately Grasp the Comprehensive Effect of "learning, Practice and Competition" and Build an Integrated Teaching Mode}

The focus of improving the quality of physical education in the new era is "learning, practice and competition". Improve the effectiveness of teaching through the innovation and improvement of various activities of "learning, practice and competition". Each of them has its own unique functions, but it is difficult to achieve the most ideal effect alone, so they need to give full play to the comprehensive effect. The relationship between the three is that learning is the basis and premise, practice is the improvement and guarantee, and competition is the test and strengthening. Action technology is the connection point of the three. Through "learning, practicing and competition", action never comes to the meeting, from quantitative change to qualitative change. There is a progressive relationship among the three, which act on the students' physical education learning process together[8].

In the process of implementing "learning, training and competition", we should grasp flexibility, pay attention to effectiveness, pay attention to innovation, and avoid formalization and complexity. In the teaching process, the purpose of "learning, training and competition" should be clear, pay attention to objectivity, follow the law, grasp the learning situation, and systematically organize various targeted activities in all links. When integrated design and systematic organization can be realized, the comprehensive effect of "learning, training and competition" can be highlighted. In addition, whether in the learning and practice links or in various competitions arranged, you can seize the opportunity to intersperse "comments", understand the learning effect in time, and improve the teaching methods in time, so as to achieve the ideal learning objectives. Form a new kind of physical education classroom teaching mode integrating "learning, practice, competition and evaluation".

\subsection{Build a Reasonable Evaluation Method}

Physical education teaching evaluation is the key guiding force of teaching reform. It is like a baton, often where the evaluation is, the results will lead to where. Therefore, it is particularly important to construct a reasonable evaluation method. According to the survey, the academic evaluation of badminton in Colleges and universities in China is often a simple "one size fits all", which is based on whether one or two technologies meet the standards or the competition results. This way can not reflect whether students have made progress and how much progress they have made. At the same time, because of the differences in students' physical quality and technical level, this evaluation method is not reasonable and fair, especially some students with poor foundation may lose their interest and enthusiasm in learning. In the evaluation of students' academic level, we should combine process evaluation and summative evaluation, qualitative evaluation and quantitative evaluation, relative evaluation and absolute evaluation, students' independent evaluation, students' mutual evaluation and teachers' evaluation. It can be evaluated from the four dimensions of "knowledge, ability, behavior and health". "Knowledge" mainly evaluates students' sports health knowledge; "Ability" mainly evaluates the level of students' special sports ability; "Behavior" mainly evaluates students' healthy behavior and moral character; "Health" mainly evaluates students' physical health level. Among them, "knowledge, ability and health" is the evaluation of the results, while "action" includes not only the evaluation of classroom learning, but also the evaluation of the cultivation of exercise behavior habits and sports morality[9].

\section{Summary}

Teaching reform is the key to improve the teaching effect of badminton in Colleges and universities. First of all, it is student-centered and takes "learning as teaching" as the teaching concept; Secondly, we should pay attention to both the construction of venues and equipment and the improvement of teachers' professional quality; Thirdly, optimize the teaching content, reasonably select the teaching content, and adopt flexible and diverse teaching methods to ensure the effectiveness of teaching and learning; Finally, improve the integrated teaching mode inside and outside the class, normalize the "church, diligent practice and regular competition", and pay attention to the reasonable and diversified evaluation of students' academic level.

\section{References}

[1] Guiding outline for teaching reform of physical education and health (Trial).

[2] Yu Sumei. An Analysis of the Implementation Strategies of the Ten Key Points of Policy [J]. Sports Journal, 2021, 28 (05): 1-13.

[3] Ji Liu, policies to improve adolescent health also need countermeasures [N]. China Education Daily, 2017-0-30 (08).

[4] Liu Junkai, Zhao Chaojun Find the focus of "church, diligent practice and regular competition" [J]. Physical Education Teaching, 2021, (01): 11-12.

[5] Xinhua News Agency. The General Office of the State Council of the General Office of the Central Committee of the Communist Party of China issued the Implementation Plan for Accelerating the Modernization of Education (2018-2022) [J]. People's Education, 2019(5): 3.

[6] Zhang Zhenhua, Ge Shulin, Interpretation and implementation of 2017 edition of physical education and health curriculum standards for senior high schools [M]. 189-190.

[7] Huang Xiunian. Two key points and precautions in badminton teaching $[\mathrm{J}]$. Science and Engineering Volume of Journal of Yangtze University (Natural Science Edition), 2008, 5(04): 384-386.

[8] Yu Sumei, Xu Hong. Interpretation of the Guiding Outline for Teaching Reform of Sports and Health [J]. Journal of Capital Institute of Physical Education, 2021, 33(04): 371-377.

[9] Yu Sumei, Focus on Deepening the Reform of Physical Education Teaching in the New Era from the Perspective of Integration [J]. Physical Education Teaching, 2020, 40 (12): $10-12$.

\section{Author Profile}


Xiunian Huang(1977-). male, PhD, Lecturer. Research in physical education. 